\title{
Physiology and Pathophysiology of Proteinase-Activated Receptors (PARs): PAR-2 as a Potential Therapeutic Target
}

\author{
Toru Kanke ${ }^{1, *}$, Toshiaki Takizawa ${ }^{1}$, Mototsugu Kabeya ${ }^{1}$, and Atsufumi Kawabata ${ }^{2}$ \\ ${ }^{I}$ Tokyo New Drug Research Laboratories, Kowa Company Limited, \\ 2-17-43 Noguchicho, Higashimurayama, Tokyo 189-0022, Japan \\ ${ }^{2}$ Division of Physiology and Pathophysiology, School of Pharmaceutical Sciences, Kinki University, \\ 3-4-1, Kowakae, Higashi-Osaka 577-8502, Japan
}

Received October 12, 2004; Accepted November 9, 2004

\begin{abstract}
PAR-2 is the second member of the family of proteinase-activated receptors activated by trypsin, tryptase, and several other serine proteinases. In order to evaluate the therapeutic potential for PAR-2, we have performed studies on PAR-2-mediated signal transduction and investigated the effects of PAR-2 gene deficiency in disease models. In addition to the Gprotein-coupled receptor-mediated common signal transduction pathways, inositol 1,4,5-trisphosphate production and mobilization of $\mathrm{Ca}^{2+}$, PAR-2 can also activate multiple kinase pathways, ERK, p38MAPK, JNK, and IKK, in a cell-type specific manner. The studies using PAR-2-genedeficient mice highlighted critical roles of PAR-2 in progression of skin and joint inflammation. We also describe the development and evaluation of potent and metabolically stable PAR-2 agonists in multiple assay systems both in vitro and in vivo. The structure-activity relationship analysis indicated the improved potencies of furoylated peptides. Furthermore, the resistance of the furoylated peptide against aminopeptidase contributed to the highly potent and sustained effects of the peptide in vivo. These studies suggest the potential therapeutic importance of PAR-2 in inflammatory diseases. Also, the PAR-2-gene-deficient mice and the potent and metabolically stable agonists are shown to be useful tools for evaluating the potency of PAR-2 as a therapeutic target.
\end{abstract}

Keywords: proteinase-activated receptor (PAR)-2, mitogen-activated peptide kinase, PAR-2-gene-deficient mice, PAR-2-activating peptide

\section{Introduction}

Identification of the family of proteinase-activated receptors implies a key role for tissue and systemic serine proteinases, not only as protein-degrading enzymes, but also as potential G-protein-coupled receptor (GPCR) activators that transmit extracellular stimuli into intracellular signalling events (reviewed in refs. 1, 2). The second member of this family of receptors, proteinase-activated receptor-2 (PAR-2), which was originally identified as a receptor activated by trypsin (3), has drawn attention by its prospective functions distinguished from other PARs activated by thrombin. Following the discovery of PAR-2, extensive studies

*Corresponding author. FAX: +81-42-395-0312

E-mail: t-kanke@kowa.co.jp have revealed that this receptor is expressed in a wide variety of epithelial and endothelial tissues (4) that have important physiological roles in regulating a wide range of biological systems, including the cardiovascular system (5) and gastrointestinal system (6), skin function (7), respiratory system (8), and peripheral nerves (9).

Although there is accumulating evidence for the involvement of PAR-2 in certain disease states, the determination of therapeutic effects and usefulness of PAR-2-targeted drugs in human disease should await the future development of specific antagonists. In this part of the review, we will present our studies, to evaluate the therapeutic potential for PAR-2, in PAR-2-mediated cellular signal transduction and in physiological responses of PAR-2-gene-deficient mice. We also will present recent developments and use of potent PAR-2 agonists as a tool to examine biological functions of 
the receptor.

\section{PAR-2-mediataed signal transduction}

Activation of PAR-2 elicits diverse cellular responses, including cell proliferation $(10,11)$, differentiation (7), and production and release of proteins such as, interleukin-6 (IL-6), granulocyte macrophage-colony stimulating factor (GM-CSF) (12), and eotaxin (13). However, signal transduction pathways leading to the diverse cellular responses remain uncharacterized. In a number of different cell types, PAR-2 effectively couples to the $\mathrm{Gq} / 11$ family G-proteins to stimulate phospholipase C (PLC) activation, resulting in generation of second messengers, inositol 1,4,5-trisphosphate $\left(\mathrm{IP}_{3}\right)$, and diacylglycerol (DG), which further trigger mobilization of $\mathrm{Ca}^{2+}$ and activation of protein kinase $\mathrm{C}$ (PKC) $(14,15)$. In addition to this common signal transduction pathway, activation of various kinase cascades, which are suggested to be key regulators of inflammatory responses, has been demonstrated. In our observation, PAR-2-mediated extracellular signal regulated kinase (ERK) activation in NCTC2544 cells was insensitive to a PKC inhibitor (Fig. 1A). On the other hand, PAR-2-mediated activation of other members of the

(A)

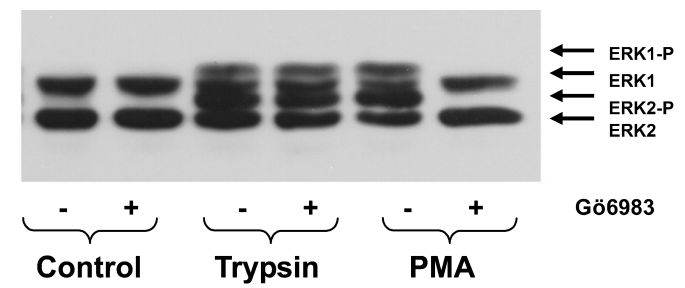

(B)
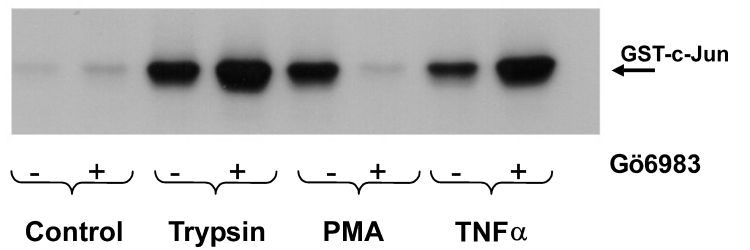

Gö6983

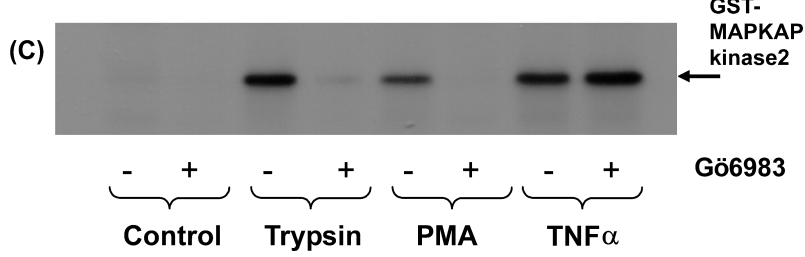

Fig. 1. Effect of PKC inhibitor Gö6983 on activation of ERK (A), JNK (B), and p38MAPK (C) in NCTC2544 cells expressing PAR-2. Cells were stimulated with either $30 \mathrm{nM}$ trypsin, $100 \mathrm{nM}$ PMA or $25 \mathrm{ng} / \mathrm{ml} \mathrm{TNF} \alpha$; and activation of kinases were determined after following time points: at $5 \mathrm{~min}$ (for ERK (A)) and at $30 \mathrm{~min}$ (for JNK (B) and p38MAPK (C)). Gö6983 $(10 \mu \mathrm{M})$ was added $15 \mathrm{~min}$ prior to the stimulation. Modified from Ref. 16 with permission. mitogen-activated protein kinase (MAPK) family, c-Jun N-terminal kinase (JNK) and p38MAPK, were partially regulated by PKC (Fig. 1: B and C). Similarly, activation of nuclear factor kappa $\mathrm{B}(\mathrm{NF} \kappa \mathrm{B})$ and its upstream regulating kinase, I kappa B kinase (IKK), were also found to be partially PKC-dependent (16). Previous studies reported selective activation of p38MAPK, whereas no activation of JNK was observed in rat aortic smooth muscle cells (17). This may imply PAR-2 transmits important cellular responses through activation of multiple kinase pathways, ERK, JNK, p38MAP kinase, and IKK, in a cell-type specific manner; and the various PKC subtypes may regulate different cellular responses. However, mechanisms for the activation of these kinase pathways need to be examined in more detail at the molecular level.

\section{Physiological studies using PAR-2-gene-deficient mice}

The effect of PAR-2 gene deletion was first described in vascular systems. Activation of PAR-2 by trypsin or PAR-2-activating peptides mediates relaxation of isolated rat aorta by an endothelium-dependent, nitric oxide (NO)-mediated mechanism (18). A study utilizing PAR2 -gene-deficient mice confirmed the in vivo function for PAR-2 in mediating vasodilation (5). In addition to regulating vascular tone, another important role for PAR-2 in vascular inflammation has been described. In endothelium, increased expression of the leukocyte adhesion molecule, P-selectin, was stimulated by PAR-2 activation, and this in turn positively regulated leukocyte accumulation, causing chronic inflammation (19). This was evidenced in a PAR-2-gene-deficient mouse study using intravital microscopy (20). These studies, combined with the early observation of increased PAR-2 mRNA expression following cytokine pre-treatment of vascular endothelial cells (21), strongly suggested a role for PAR-2 in the integration of vascular inflammation. Similar mechanisms may be responsible in our observation on contact-induced skin inflammation, which was abrogated in PAR-2-gene-deficient mice (22). Another line of evidence for PAR-2 in association with chronic inflammation was demonstrated in an adjuvant monoarthritis model (23). Disruption of the PAR-2 gene results in ablation of chronic arthritis both at levels of joint swelling (Fig. 2A) (23) and in histological evaluation. Up-regulation of PAR-2 in inflamed synovial tissues was also demonstrated in the arthritis, suggesting the pro-inflammatory effects of PAR-2 mainly at the local tissues. However, involvement of PAR-2 in immune responses should also be considered, as the effect of PAR-2 on dendritic cell development (24). Other reports using PAR-2-gene-deficient mice demon- 
(A)

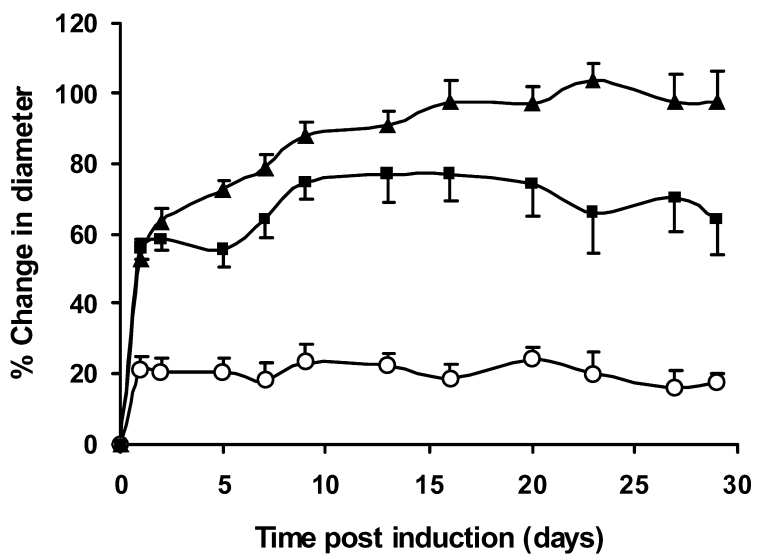

(B)

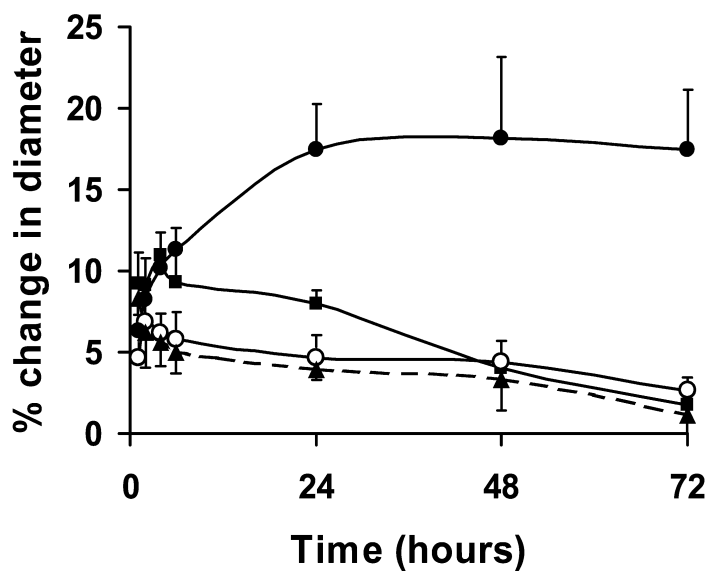

Fig. 2. (A) Effect of PAR-2 gene disruption in adjuvant arthritis. Comparison of the response to induction of adjuvant arthritis in PAR-2+/+ mice (closed triangle), PAR-2-/- mice (open circle), and heterozygous mice (closed square). (B) Joint swelling induced by intra-articular injection of SLIGRL (closed square), ASKH95 (closed circle), or control peptide (closed triangle) in PAR-2+/+ mice and ASKH95 (open circle) in PAR-2-/- mice. Modified from Ref. 23 with permission.

strated important roles of PAR-2 in hyperalgesia (25) and intestinal inflammation (26), which may coordinate neurogenic inflammation and pain. Further application of PAR-2-gene-deficient mice in other physiological systems will provide direct evidence for important physiological roles of PAR-2 in other tissues and disease states. In addition to evaluation of biological functions of the receptor, the PAR-2-gene-deficient mice, and tissues and cells derived from them, can be utilized to assess the selectivity of agonists and antagonists.

\section{PAR-2 agonists and antagonists}

The synthetic agonist peptides mimicking the tethered ligand of PAR-2, SLIGKV-OH (human), SLIGRL-OH (mouse/rat) $(3,27)$, and their amidated forms SLIGKV$\mathrm{NH}_{2}$ and SLIGRL-NH $(14,18)$ were also shown to be
Table 1. $\mathrm{EC}_{50}$ or $\mathrm{ED}_{50}$ values and the relative potency of PAR-2activating peptides

\begin{tabular}{lccc}
\hline & \multicolumn{2}{c}{ EC $_{50}$ or $\mathrm{ED}_{50}$ (Relative potency) } \\
\cline { 2 - 4 } & $\begin{array}{c}\mathrm{Ca}^{2+} \text { response in } \\
\text { HCT-15 cells }\end{array}$ & $\begin{array}{c}\text { Salivation } \\
\text { Amastatin (-) }\end{array}$ & Amastatin (+) \\
\hline SLIGKV-OH & $22.8(1)$ & $32.9(1)$ & $31.7(1)$ \\
SLIGRL-OH & $7.87(2.90)$ & $9.95(3.31)$ & $7.86(4.03)$ \\
SLIGKV-NH & $5.05(4.51)$ & $11.4(2.88)$ & $3.10(10.2)$ \\
SLIGRL-NH & $3.13(7.28)$ & $2.84(11.6)$ & $0.250(127)$ \\
2f-LIGKV-OH & $1.68(13.6)$ & $0.840(39.2)$ & $0.690(45.9)$ \\
2f-LIGRL-OH & $1.21(18.8)$ & nd & nd \\
2f-LIGKV-NH & $0.318(71.7)$ & $0.070(470)$ & $0.0600(528)$ \\
2f-LIGRL-NH & $0.253(90.1)$ & $0.0300(1100)$ & $0.0400(793)$ \\
\hline
\end{tabular}

$\mathrm{EC}_{50}(\mu \mathrm{M})$ and $\mathrm{ED}_{50}(\mu \mathrm{mol} / \mathrm{kg})$ were calculated in each assay system. The relative potency shown in parentheses was calculated by an equation, $\left(\mathrm{EC}_{50}\right.$ or $\mathrm{ED}_{50}$ of SLIGKV-OH $) /\left(\mathrm{EC}_{50}\right.$ or $\mathrm{ED}_{50}$ of each peptide). nd, not determined. Modified from Ref. 28 with permission.

able to activate the receptor without enzymatic cleavage. In addition to the original PAR-2 activating peptides, a series of potent PAR-2 agonists, by modification of the native PAR-2-activating peptides substituted with 2furoyl on the N-terminal serine, have been described recently. The initial identification was achieved by Plevin's group who showed that 2-furoyl-LIGKV-OH (ASKH95) exhibited potent PAR-2 agonist activity in the cellular inositol phosphate assay, and strikingly, the intra-articular injection of the modified peptide resulted in sustained joint swelling in mice (Fig. 2B) (23). In the follow-up studies, detailed structure-activity relationships of a series of 2-furoyl agonist peptides have been examined in multiple assays, cellular $\mathrm{Ca}^{2+}$ mobilization, rat mesenteric artery relaxation, and saliva secretion in mice, demonstrating that 2-furoyl-LIGRL- $\mathrm{NH}_{2}$ has the highest PAR-2-activating potency (Table 1) (28). Additionally, the increased resistance of furoylated peptides to a peptide-metabolizing enzyme, aminopeptidase, resulted in dramatic increase in PAR-2-activating potency in vivo (Fig. 3B) (28). Consistent with this observation, an independent study also described a similar modified peptide, 2-furoyl-LIGRLO-NH ${ }_{2}$, as a potent PAR-2activating peptide (29). It is not clear whether the addition of C-terminal ornithine alters the PAR-2 agonistic activity; nevertheless, it is clear that 2-furoyl peptides are the most potent agonistics currently available, which are useful in for evaluating PAR-2 function.

As for the PAR-2 antagonists, currently very little information is available. In the studies on structureactivity relationships (SARs) of PAR-1-activating peptides, substitution of the $\mathrm{N}$-terminal serine with a neutral hydrophobic $\mathrm{N}$-acyl group (e.g., trans-cinnamoyl group) provided peptides that were partial agonists or antago- 
(A)

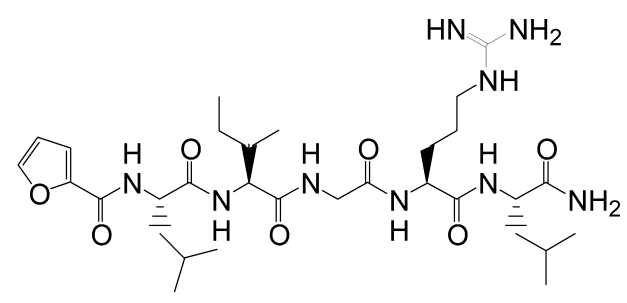

(B)

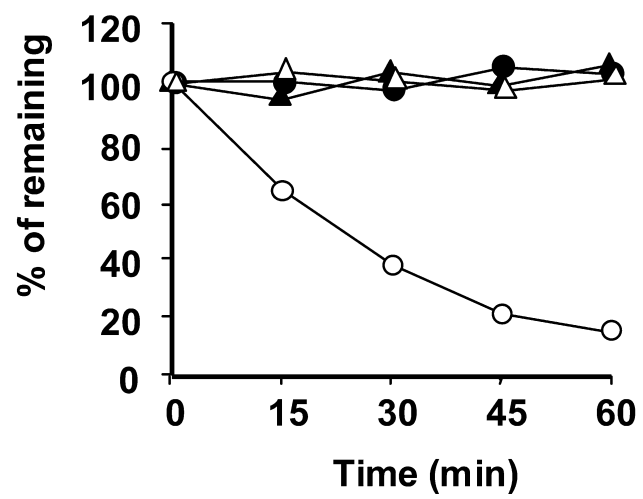

Fig. 3. Structure of 2-furoyl-LIGRL- $\mathrm{NH}_{2}$ (A) and metabolic stability of PAR-2-activating peptides in vitro (B). The peptide $(50 \mu \mathrm{g} / \mathrm{ml})$ was incubated with aminopeptidase $(0.2 \mathrm{U} / \mathrm{ml})$ for $0-$ $60 \mathrm{~min}$ in the absence [SLIGRL-NH ${ }_{2}$ (open circle), 2-furoyl-LIGRL$\mathrm{NH}_{2}$ (open triangle)] or presence [SLIGRL- $\mathrm{NH}_{2}$ (closed circle), 2furoyl-LIGRL- $\mathrm{NH}_{2}$ (closed triangle)] of amastatin $(2.5 \mu \mathrm{M})$. Data show the mean values of duplicate experiments. Modified from Ref. 28 with permission.

nists for PAR-1 (30). In contrast, the similar modification on PAR-2 agonist peptides provided peptides with agonistic activity, for example, trans-cinnamoylLIGRLO-NH $\mathrm{N}_{2}$ (31). In a study on peptides derived from PAR-2 agonist peptides, two peptides, FSLLRY-NH ${ }_{2}$ and LSIGRL-NH $\mathrm{N}_{2}$, have been described to antagonize trypsin-induced PAR-2 activation (32). However, these peptides are unable to antagonize PAR-2-activating peptides, suggesting these peptides bind to the receptortrypsin association site, although its exact mechanism is not clear. So far, currently no clear antagonists for PAR-2 have been reported; however, the SARs on PAR2 agonist peptides and related peptides may provide useful information for future development of PAR-2 antagonists.

\section{PAR-2 as a therapeutic target}

As presented, a number of studies both in vitro and in vivo implicate PAR-2 in the mediation of inflammatory responses. The mechanisms of PAR-2-elicited inflammation consist of multiple cascades, including increase of vascular permeability, cytokine production, and expression of adhesion molecules that further lead to leukocyte accumulation (19). Additionally, PAR-2stilumated secretion of prostanoids (33) and NO (34) may enhance the inflammatory responses, while activation of PAR-2 in nerve endings induces the release of calcitonin gene-related peptide (CGRP) and substance $P$ (35). Therefore, the future development of PAR-2 antagonists can be therapeutically beneficial for treatment of a number of inflammatory diseases such as allergic dermatitis, rheumatoid arthritis, asthma, inflammatory bowel disease, and neurogenic pain.

Several important physiological roles of PAR-2 in maintaining homeostatic biological functions have also been described in several organs such as secretary glands (36), kidney (37), and respiratory systems (8). Therefore, in these situations, loss of PAR-2 expression and dysfunction of the receptor may cause diseases. Potent and stable PAR-2 agonists such as 2-furoylpeptides can be powerful tools to explore these possibilities.

\section{Acknowledgments}

A large part of our studies on PAR-2 has been performed in a collaborative research project with Scottish Universities: Strathclyde University (Prof. R. Plevin), Edinburgh University (Prof. R. Ramage), Centre for Genome Research (Dr. A.J.H. Smith), Glasgow University (Prof. W.R. Ferrell), and Paisley University (Dr. J.C. Lockhart), supported by Scottish Biomedical and Kowa Company. We also acknowledge Dr. M. Iwaki of Kinki University for metabolic characterization of furoylated peptides.

\section{References}

1 Macfarlane SR, Seatter MJ, Kanke T, Hunter GD, Plevin R. Proteinase-activated receptors. Pharmacol Rev. 2001;53:245282.

2 Hollenberg MD, Compton SJ. International Union of Pharmacology. XXVIII. Proteinase-activated receptors. Pharmacol Rev. 2002;54:203-217.

3 Nystedt S, Emilsson IE, Wahlestedt C, Sundelin J. Molecularcloning of a potential proteinase activated receptor. 1994;91: 9208-9212.

4 D'Andrea MR, Derian CK, Leturcq D, Baker SM, Brunmark A, Ling $\mathrm{P}$, et al. Characterization of protease-activated receptor-2 immunoreactivity in normal human tissues. J Histochem Cytochem. 1998;46:157-164.

5 Damiano BP, Cheung WM, Santulli RJ, FungLeung WP, Ngo K, Ye RD, et al. Cardiovascular responses mediated by proteaseactivated receptor-2 (PAR-2) and thrombin receptor (PAR-1) are distinguished in mice deficient in PAR-2 or PAR-1. 1999;288:671-678.

6 Kawabata A. PAR-2: structure, function and relevance to human 
diseases of the gastric mucosa. Expert Rev Mol Med. 2002;4:117.

7 Derian CK, Eckardt AJ, Andrade Gordon P. Proteinase-activated receptor-2 inhibits cell growth and differentiation of human epidermal keratinocytes. 1996;106:409.

8 Cocks TM, Fong B, Chow JM, Anderson GP, Frauman AG, Goldie RG, et al. A protective role for protease-activated receptors in the airways. Nature. 1999;398:156-160.

9 Vergnolle N, Wallace JL, Bunnett NW, Hollenberg MD. Protease-activated receptors in inflammation, neuronal signaling and pain. Trends Pharmacol Sci. 2001;22:146-152.

10 Mirza H, Yatsula V, Bahou WF. The proteinase activated receptor-2 (PAR-2) mediates mitogenic responses in human vascular endothelial cells. J Clin Invest. 1996;97:1705-1714.

11 Akers IA, Parsons M, Hill MR, Hollenberg MD, Sanjar S, Laurent GJ, et al. Mast cell tryptase stimulates human lung fibroblast proliferation via protease-activated receptor-2. 2000; 278:L193-L201.

12 Wakita H, Furukawa F, Takigawa M. Thrombin and trypsin induce granulocyte-macrophage colony-stimulating factor and interleukin-6 gene expression in cultured normal human keratinocytes. Proc Assoc Am Physicians. 1997;109:190-207.

13 Vliagoftis H, Befus AD, Hollenberg MD, Moqbel R. Airway epithelial cells release eosinophil survival-promoting factors (GM-CSF) after stimulation of proteinase-activated receptor 2. J Allergy Clin Immunol. 2001;107:679-685.

14 Bohm SK, Kong WY, Bromme D, Smeekens SP, Anderson DC, Connolly A, et al. Molecular cloning, expression and potential functions of the human proteinase-activated receptor-2. 1996; 314:1009-1016

15 Molino M, Woolkalis MJ, Reavey Cantwell J, Pratico D, Andrade Gordon P, Barnathan ES, et al. Endothelial cell thrombin receptors and PAR-2 - Two protease-activated receptors located in a single cellular environment. 1997;272: 11133-11141.

16 Kanke T, Macfarlane SR, Seatter MJ, Davenport E, Paul A, McKenzie RC, et al. Proteinase-activated receptor-2-mediated activation of stress-activated protein kinases and inhibitory kappa B kinases in NCTC 2544 keratinocytes. J Biol Chem. 2001;276:31657-31666.

17 Belham CM, Scott PH, Tate RJ, Wadsworth RM, Plevin R. Proteinase-activated receptor-2-dependent activation of mitogen-activated protein kinases in rat aortic smooth muscle cells. 1996;119:10.

18 Hollenberg MD, Saifeddine M AlAni B. Proteinase-activated receptor-2 in rat aorta: structural requirements for agonist activity of receptor-activating peptides. 1996;49:229-233.

19 Vergnolle N. Proteinase-activated receptor-2-activating peptides induce leukocyte rolling, adhesion, and extravasation in vivo. 1999;163:5064-5069.

20 Lindner JR, Kahn ML, Coughlin SR, Sambrano GR, Schauble E, Bernstein D, et al. Delayed onset of inflammation in proteaseactivated receptor-2-deficient mice. J Immunol. 2000;165:65046510 .

21 Nystedt S, Ramakrishnan V, Sundelin J. The proteinase-activated receptor 2 is induced by inflammatory mediators in human endothelial cells-comparison with the thrombin receptor. 1996;271:14910-14915.

22 Kawagoe J, Takizawa T, Matsumoto J, Tamiya M, Meek SE,
Smith AJ, et al. Effect of protease-activated receptor-2 deficiency on allergic dermatitis in the mouse ear. Jpn J Pharmacol. 2002;88:77-84.

23 Ferrell WR, Lockhart JC, Kelso EB, Dunning L, Plevin R, Meek $\mathrm{SE}$, et al. Essential role for proteinase-activated receptor-2 in arthritis. J Clin Invest. 2003;111:35-41.

24 Fields RC, Schoenecker JG, Hart JP, Hoffman MR, Pizzo SV Lawson JH. Protease-activated receptor-2 signaling triggers dendritic cell development. Am J Pathol. 2003;162:1817-1822.

25 Vergnolle N, Bunnett NW, Sharkey KA, Brussee V, Compton SJ, Grady EF, et al. Proteinase-activated receptor-2 and hyperalgesia: a novel pain pathway. Nat Med. 2001;7:821-826.

26 Cenac N, Coelho AM, Nguyen C, Compton S, Andrade-Gordon $\mathrm{P}$, MacNaughton WK, et al. Induction of intestinal inflammation in mouse by activation of proteinase-activated receptor-2. Am J Pathol. 2002;161:1903-1915.

27 Nystedt S, Larsson AK, Aberg H Sundelin J. The mouse proteinase-activated receptor-2 cDNA and gene. Molecular cloning and functional expression. J Biol Chem. 1995;270: 5950-5955.

28 Kawabata A, Kanke T, Yonezawa D, Ishiki T, Saka M, Kabeya $\mathrm{M}$, et al. Potent and metabolically stable agonists for proteaseactivated receptor-2: evaluation of activity in multiple assay systems in vitro and in vivo. J Pharmacol Exp Ther. 2004;309:1098-1107.

29 McGuire JJ, Saifeddine M, Triggle CR, Sun K, Hollenberg MD. 2-furoyl-LIGRLO-amide: a potent and selective proteinaseactivated receptor 2 agonist. J Pharmacol Exp Ther. 2004;309: 1124-1131.

30 Bernatowicz MS, Klimas CE, Hartl KS, Peluso M, Allegretto NJ, Seiler SM. Development of potent thrombin receptor antagonist peptides. J Med Chem. 1996;39:4879-4887.

31 Roy SS, Saifeddine M, Loutzenhiser R, Triggle CR Hollenberg MD. Dual endothelium-dependent vascular activities of proteinase-activated receptor-2-activating peptides: evidence for receptor heterogeneity. Br J Pharmacol. 1998;123:1434-1440.

32 Al-Ani B, Saifeddine M, Wijesuriya SJ, Hollenberg MD. Modified proteinase-activated receptor- 1 and -2 derived peptides inhibit proteinase-activated receptor- 2 activation by trypsin. J Pharmacol Exp Ther. 2002;300:702-708.

33 Kong W, Khitin L, Liddle RA, Coughlin SR, Payan DG, Kirkwood K, et al. Proteinase-activated receptor 2 (PAR-2) regulates prostaglandin secretion and $\mathrm{CCK}$ release from intestinal epithelial cells. 1996;110:A1089.

34 Emilsson K, Wahlestedt C, Sun MK, Nystedt S, Owman C, Sundelin J. Vascular effects of proteinase-activated receptor 2 agonist peptide. 1997;34:267-272.

35 Steinhoff M, Vergnolle N, Young SH, Tognetto M, Amadesi S, Ennes HS, et al. Agonists of proteinase-activated receptor 2 induce inflammation by a neurogenic mechanism. Nat Med. 2000;6:151-158.

36 Kawabata A, Nishikawa H, Kuroda R, Kawai K Hollenberg MD. Proteinase-activated receptor-2 (PAR-2): regulation of salivary and pancreatic exocrine secretion in vivo in rats and mice. Br $\mathrm{J}$ Pharmacol. 2000;129:1808-1814.

37 Gui Y, Loutzenhiser R, Hollenberg MD. Bidirectional regulation of renal hemodynamics by activation of PAR1 and PAR2 in isolated perfused rat kidney. Am J Physiol Renal Physiol. 2003;285:F95-F104. 